\title{
High resolution computed tomography in patients referred for intraluminal bronchoscopic therapy with curative intent
}

\author{
G. Sutedja*, R.P. Golding**, P.E. Postmus*
}

High resolution computed tomography in patients referred for intraluminal bronchoscopic therapy with curative intent. G. Sutedja, R.P. Golding, P.E. Postmus. CERS Journals Ltd 1996.

ABSTRACT: In patients with so-called roentgenologically occult intraluminal lung tumours, an accurate assessment of tumour size, its location and peribronchial tumour extent is important prior to any intraluminal bronchoscopic therapy (IBT) with curative intent.

In twenty patients with so-called occult early-stage lung cancers, clinical outcome was compared to high resolution computed tomography (HRCT) findings prior to IBT.

HRCT showed peribronchial tumour extension or nodal enlargement in 7 of the 20 patients $(35 \%)$, and consequently treatment policy was changed. Five of the seven died 1.5-6 months after diagnosis, one patient underwent a radical pneumonectomy after induction chemotherapy, and the remaining patient is alive with pleural metastasis. HRCT showed intraluminal tumours in 11 of the 20 patients and IBT with curative intent was given. Complete response (CR) was achieved in 10 of the 11 patients, follow-up has been 4-26 months. One patient underwent a radical lobectomy, pathological stage T1N0, after 3 months because of tumour recurrence. HRCT was inconclusive in 2 of the 20 patients with postobstructive infiltrates. IBT was unsuccessful in both these cases.

High resolution computed tomography may provide supportive evidence of intraand extraluminal tumour; thereby, helping in the assessment of patients who were judged to be suitable for intra-luminal bronchoscopic therapy with curative intent. This may lead to a change in the treatment policy.

High resolution computed tomography findings are complementary to bronchoscopic, histological and cytological examinations for the proper evaluation of treatment indications in patients with occult lung cancer.

Eur Respir J., 1996, 9, 1020-1023.
Depts of *Pulmonary Medicine and **Radiology, Free University Hospital Amsterdam, Amsterdam, The Netherlands.

Correspondence T.G. Sutedja Dept of Pulmonary Medicine Free University Hospital PO Box 7057

1007 MB Amsterdam

The Netherlands

Keywords: Bronchoscopic treatment high reolution computed tomography occult lung cancer

Received: May 31995

Accepted after revision January 91996
Currently, intraluminal bronchoscopic treatment (IBT) may be used in the management of endobronchial tumours. Treatment modalities include the neodymium-yttrium aluminium garnet (Nd-YAG) laser, brachytherapy, photodynamic therapy (PDT) and electrosurgery $[1,2]$. Although these techniques are mainly used for palliation, treatment with curative intent may be performed in patients with roentgenologically occult, early-stage lung cancer [3-9]. It is important to assess as accurately as possible intra- and extraluminal tumour extent prior to IBT [10-13]. Conventional radiological examinations and standard computed tomography (CT) have been reported to be relatively inaccurate for this purpose [12, 13]. Bronchoscopy poorly predicts peribronchial tumour extent and cannot evaluate the presence of nodal disease. The success of IBT is strongly related to these factors and, together with tumour size, they are important determinants for the therapeutic approach $[2-5,9]$. We have performed a prospective study to determine whether high resolution computed tomography (HRCT) may provide additional information in patients referred for IBT with curative intent.

\section{Materials and methods}

Twenty patients, 18 males and 2 females, median age 68 (range 56-80) yrs, were referred to our clinic for IBT. The reason for referral was in all cases documented malignancies, which were inoperable or marginally operable because of previous resection or limited pulmonary function. These indications for IBT with curative intent are shown in table 1. Patients were considered suitable for IBT if intraluminal tumour size was $\leq 2 \mathrm{~cm}$, with visible

Table 1. - Indication for intraluminal bronchoscopic treatment and number of patients per category

\begin{tabular}{|c|c|}
\hline Indication category & Pts $n$ \\
\hline $\begin{array}{l}\text { Inoperable because of limited pulmonary function } \\
\text { (e.g. previous resection) }\end{array}$ & 9 \\
\hline Second primary after previous resection & 1 \\
\hline Synchronous tumour, second intraluminal tumour & 3 \\
\hline Resectable tumours, but marginal pulmonary function & 7 \\
\hline
\end{tabular}

Pts: patients 
Table 2. - Comparison between bronchoscopic and HRCT findings

\begin{tabular}{|c|c|c|c|c|c|c|}
\hline \multicolumn{2}{|c|}{ Bronchoscopic findings } & \multicolumn{4}{|c|}{ HRCT diagnostic groups } & \multirow[b]{2}{*}{ Nodal } \\
\hline $\begin{array}{l}\text { Intraluminal } \\
\text { tumour size }\end{array}$ & $\begin{array}{c}\text { Pts } \\
\mathrm{n}\end{array}$ & Invisible & Intraluminal & Extraluminal & Infiltrates & \\
\hline Superficial $<1 \mathrm{~cm}^{2}$ & 9 & 7 & $2(1 *)$ & \multirow{4}{*}{$\begin{array}{l}3(2 *) \\
2\end{array}$} & & $1 *$ \\
\hline $1-2 \mathrm{~cm}^{2}$ & 7 & & 3 & & 1 & $2 *$ \\
\hline Bronchial thickening & 2 & & & & & \\
\hline Invisible distal margin & 2 & & 1 & & 1 & \\
\hline Total pts $\mathrm{n}$ & 20 & 7 & 6 & 5 & 2 & 3 \\
\hline
\end{tabular}

proximal margin and without peribronchial tumour extension or nodal enlargement on standard CT examinations. Measurements of tumour size and width were made using the distance between the jaws of the biopsy forceps and the distal to proximal displacement of these forceps or bronchoscope at the nasal orifice. In two patients with synchronous cancers, IBT was performed 4-6 weeks after radical surgery of the more advanced tumour. Bronchoscopy was performed prior to treatment to evaluate treatment indication. Tumours were assessed in terms of length axis, circumference and thickness. Bronchial wall thickening or the invisibility of the distal tumour margin was also documented.

Patients underwent CT scanning (Somatom Plus®; Siemens, Erlangen, Germany) in the supine position with maximal inspiratory breathholding duration of $24 \mathrm{~s}$, during which data acquisition was obtained with the spiral technique using the following factors: Ma 145, kV 137, table feed $2 \mathrm{~mm}$, slice thickness and reconstruction 2 $\mathrm{mm}$ (pitch=1). One hundred millilitres of intravenous contrast (Ultravist ${ }^{\circledR}$; Schering), a nonionic, low osmolality monomeric medium, was injected using a powered pump (Medrad Mark IV®, PA, USA) at a flow rate of $2 \mathrm{~mL} \cdot \mathrm{s}^{-1}, 150$ pounds per square inch pressure and a linear rise of $0.1 \mathrm{~s}$, with a minimum effective delay before screening of $23 \mathrm{~s}$. The area to be screened was agreed in consultation with the bronchoscopist and the findings of the conventional CT scan, consisting of contiguous $10 \mathrm{~mm}$ slices of the whole thorax, which preceded the spiral scan in every case. The maximum scan length was $44 \mathrm{~mm}$ and images were "zoomed" to the major airways and photographed at approximately $-500 / 1500$ settings.

The technique produced very good delineation of the major blood vessels and airways. Attempts early in the series to produce three dimensional images (Voxel Q; Picker, Ohio, USA) whilst of some value for the intraluminal bronchial spaces were disappointing for the mediastinal peribronchial tissues, and were later discontinued. However, both intraluminal and extraluminal tumour extension were clearly visible on the axial slices. Extraluminal tissue which showed the same degree of enhancement as intraluminal tumour was considered to have an identical vascular pattern with regard to contrast access to both the capillary network and the extracapillary interstitial space. Since such similar contrast enhancement occurred over a very short space of time and in a very small area, extraluminal tissue with this appearance was considered to consist of tumour. The radiologist described tumours as being invisible (HRCT occult), intraluminal, extraluminal showing bronchial wall irregularities/ peribronchial invasion, or as having nodes more than 1 $\mathrm{cm}$ in diameter. If HRCT revealed extraluminal disease or nodal enlargement, IBT was considered inappropriate for achieving cure and alternative treatment was given. Images showing postobstructive infiltrates were considered inconclusive. Both HRCT and bronchoscopic evaluations were repeated at 3 month intervals in patients receiving IBT. A complete response was defined when bronchoscopy, histology, cytology and HRCT were negative for tumour.

\section{Results}

The correlation between bronchoscopic and HRCT findings is shown in table 2. HRCT showed tumours to be intraluminal without nodal enlargement in 11 patients, who were then treated with IBT with curative intent. Nine patients are currently alive showing a complete response (CR) 4-26 months post-IBT (median 10 months). Of the two remaining patients, one died of cardiac causes 8 months post-IBT (CR at 6 months), and one underwent a radical lobectomy, pathological stage T1N0, at 3 months post-IBT because of tumour recurrence. HRCT showed the presence of peribronchial tumour extension and/or nodal enlargement in seven patients (35\%) and, consequently, treatment policy was changed. The clinical outcome of these patients was compatible with advanced tumours, as shown in table 3.

Table 3. - Follow-up data of seven patients, in whom treatment change was made due to HRCT findings of peribronchial/nodal involvement

\begin{tabular}{|c|c|c|c|}
\hline $\begin{array}{l}\mathrm{Pt} \\
\text { No. }\end{array}$ & $\begin{array}{l}\text { HRCT } \\
\text { findings }\end{array}$ & Treatments & Follow-up (months) \\
\hline 2 & EL & Nd-YAG $\#$ & Died, haemoptysis (6) \\
\hline 3 & Nodal & $\begin{array}{l}\text { Electrosurgery\# } \\
+\mathrm{RT}\end{array}$ & Died, brain metastasis (6) \\
\hline 6 & Nodal & None & Died, mediastinal disease (4) \\
\hline 7 & EL & $\begin{array}{l}\text { Induction } \\
\text { chemotherapy }\end{array}$ & $\begin{array}{l}\text { Radical surgery, patholog- } \\
\text { ical stage T3N0, alive (15) }\end{array}$ \\
\hline 8 & EL & None & Died, bone metastasis (5) \\
\hline 11 & EL & RT & Alive, pleural metastasis (5) \\
\hline 13 & $\begin{array}{r}\text { EL+ } \\
\text { Nodal }\end{array}$ & RT & Died, haemoptysis (1.5) \\
\hline
\end{tabular}

EL: extraluminal; RT: radiotherapy; Pt: patient; HRCT: high resolution computed tomography; IBT: intraluminal bronchoscopic therapy; Nd-YAG: neodymium-yttrium aluminium garnet. \#: palliative IBT to prevent obstructive pneumonia and lacking treatment alternative. 
HRCT showed poststenotic infiltrates in two patients. IBT was performed to open the segmental bronchi and residual tumour was found distally after treatment. One patient underwent a radical lobectomy (pathological stage T1N0) and another was again treated with IBT because alternative treatment was lacking.

\section{Discussion}

Endobronchial tumours can be treated using various bronchoscopic methods [1, 2]. Previous reports have shown the efficacy of IBT for early-stage squamous cell cancers either by applying photodynamic therapy or brachytherapy [3-9]. The outcome of treatment depends strongly on the dimension of the tumour and the ability to delineate the distal tumour margin during IBT $[4,5]$.

Previous data have indicated the importance of accurate tumour assessment, as intraluminal lung cancer $\leq 3$ $\mathrm{mm}$ deep and $\leq 2 \mathrm{~cm}$ long were pathological stage T1N0 on resection [10-13]. These tumours are, therefore, considered suitable for IBT with curative intent as an alternative to surgical resection [1-3].

HRCT provides a better spatial resolution by using a different reconstruction algorithm [14]. CT or HRCT may provide more accurate assessment of roentgenologically occult tumours in candidates for IBT [15], by showing the presence of a more "advanced" tumour or nodal enlargement. CT has been reported to be useful in assessing the vascular anatomy and predicting response to palliative laser therapy for large bulky tumours [16-17]. Although conventional $\mathrm{CT}$ in patients with bronchial pathology was shown to be $63-85 \%$ sensitive in detecting airway abnormalities, it was shown to be relatively inaccurate in differentiating mucosal abnormalities, intra- and extraluminal tumour [18]. Magnetic resonance imaging was found to be inferior to $\mathrm{CT}$, with a $50 \%$ detection rate for bronchial abnormalities [19]. The use of HRCT to evaluate very small bronchial abnormalities in patients with haemoptysis is obvious [20]. HRCT using $1.5 \mathrm{~mm}$ sections was able to identify discrete endobronchial lesions in five patients with haemoptysis. The better spatial resolution of HRCT may, therefore, be useful for our purpose to evaluate occult early stage lung cancer [10-13]. It might be argued that HRCT is not necessarily more helpful in indicating nodal enlargement as accuracy is only $\pm 50 \%$, but our study was aimed at accurately assessing tumour size and margins prior to IBT.

Ideally, the best evidence of HRCT accuracy would be the histological proof of peribronchial tumour in the resected surgical specimens. However, the new approach of IBT for marginally operable patients having occult lung tumours may limit recruitment of a sufficient number of patients to be studied in this particular way. Therefore, a prospective study to evaluate this seems unwarranted. The second best way to assess HRCT accuracy is by comparing HRCT findings to clinical outcome. We used HRCT as an addition to bronchoscopy, in either excluding or confirming the presence of peribronchial disease in patients with occult, early stage squamous cell lung cancer, as bronchoscopy cannot assess the peribronchial compartment. In our series, HRCT results led to a change in treatment policy in $35 \%$ of the cases. Clinical data were compatible with relatively advanced tumour, the presence of which was suggested by HRCT, despite the lack of histological proof (table 3). In patients considered to be good candidates for IBT after HRCT, the clinical outcome was supportive for the value of HRCT in the detection of early stage tumours, as most patients are still in complete response. Histological proof obtained from surgically resected specimens could not be provided, as many patients were high risk candidates for surgical resection due to poor pulmonary function. However, the criteria for early stage lung cancer in these patients had been met bronchoscopically prior to treatment. The curative potential of IBT has been reported in this category of patients using various techniques [1-13].

With HRCT and bronchoscopy there may be difficulties in assessing tumours causing postobstructive infiltrates, as can be seen in our two patients. IBT is not recommended in this category of patients, as reports have indicated that tumours located peripherally are usually more advanced [13] and that the difficulty in assessing the distal tumour margin may limit treatment efficacy [4, $5]$.

Bronchoscopic histological and cytological examinations must be performed at follow-up, as HRCT cannot differentiate fibrotic changes from tumour recurrence so that HRCT may only be complementary to bronchoscopy in evaluating extraluminal disease progression or nodal disease. The limited number of patients undergoing IBT in which HRCT correctly predicted extraluminal disease progression and the relatively short follow-up period, do not justify any firm conclusion about the value of HRCT during follow-up.

In summary, high resolution computed tomography may be complementary to bronchoscopy for the evaluation of treatment policy in patients with roentgenologically occult lung cancer by providing information about extraluminal tumour extent indicating the presence of advanced disease rather than early stage lung tumour.

\section{References}

1. Cortese DA, Edell ES. Role of phototherapy, laser therapy, brachytherapy and prosthetic stents in the management of lung cancer. Mayo Clin Proc 1993; 14: 149-159.

2. Sutedja G, Postmus PE. Bronchoscopic treatment in lung cancer. A review. Lung Cancer 1994; 11: 1-17.

3. Edell ES, Cortese DA. Photodynamic therapy in the management of early superficial squamous cell carcinoma as an alternative to surgical resection. Chest 1992; 102: 1319-1322.

4. Furuse K, Fukuoka M, Kato H, et al. A prospective phase II study on photodynamic therapy with photofrin II for centrally located early-stage lung cancer. J Clin Oncol 1993; 11: 1852-1857.

5. Sutedja G, Lam S, LeRiche JC, Postmus PE. Response and pattern of failure after photodynamic therapy for intraluminal stage I lung cancer. J Bronch 1994; 1: 295-298.

6. O'Driscoll BR, Burt PA, Stout R, Barber PV. Radical treatment of lung cancer by high dose rate intraluminal radiotherapy. Am Rev Respir Dis 1991; 143: A60.

7. Sutedja G, Baris G, van Zandwijk N, Postmus PE. High dose rate brachytherapy has a curative potential in patients with intraluminal squamous cell lung cancer. Respiration 1993; 61: 167-168. 
8. Hernandez P, Donath D. High dose rate endobronchial brachytherapy in the treatment of bronchogenic carcinoma. Chest 1993; 104: 989-990.

9. Ono R, Hirano H, Egawa S, Suemasu K. Bronchoscopic ultrasonography and brachytherapy in roentgenologically occult bronchogenic carcinoma. J Bronch 1994; 1: 281287.

10. Woolner LB, Fontana RS, Cortese DA, et al. Roentgenographically occult lung cancer: pathologic findings and frequency of multicentricity during a 10 year period. Mayo Clin Proc 1984; 59: 453-466.

11. Nagamoto N, Saito Y, Ohta S, et al. Relationship of Iymph node metastasis to primary tumor size and microscopic appearance of roentgenographically occult lung cancer. Am J Surg Pathol 1989; 13: 1009-1013.

12. Usuda K, Saito Y, Nagamoto N, et al. Relation between bronchoscopic findings and tumor size of roentgenographically occult bronchogenic squamous cell carcinoma. J Thorac Cardiovasc Surg 1993; 106: 1098-1103.

13. Akaogi E, Ogawa I, Mitsui K, et al. Endoscopic criteria of early squamous cell carcinoma of the bronchus. Cancer 1994; 74: 3113-3117.

14. Aberle DA, Brown K, Young DA, Batra P, Steckel RJ. Imaging techniques in the evaluation of tracheobronchial neoplasms. Chest 1991; 99: 211-215.
15. Naidich DP, Lee JJ, Garay SM, McCauley DI, Aranda $\mathrm{CP}$, Boyd AD. Comparison of CT and fiberoptic bronchoscopy in the evaluation of bronchial disease. AJR 1987; 148: 1-7.

16. Zwirewich CV, Muller NL, Lam S. Photodynamic laser therapy to alleviate complete bronchial obstruction: comparison of CT and bronchoscopy to predict outcome. AJR 1988; 151: 897-901.

17. Pearlberg JL, Sandler MA, Kvale P, Beute GH, Madrazo BL. Computed-tomographic and conventional lineartomographic evaluation of tracheobronchial lesions for laser photoresection. Radiology 1985; 154: 759-762.

18. Colice GL, Chappel GJ, Frenchman SM, Solomon DA. Comparison of computed tomography with fiberoptic bronchoscopy in identifying endobronchial abnormalities in patients with known or suspected lung cancer. Am Rev Respir Dis 1985; 131: 397-400.

19. Mayr B, Heywang SH, Ingrisch H, Huber RM, Haussinger $\mathrm{K}$, Lissner J. Comparison of CT with MR imaging of endobronchial tumors. J Comput Assist Tomogr 1987; 11: 43-48.

20. McGuiness G, Beacher J, Harkin TJ, Garay SM, Rom WN, Naidich DP. Hemoptysis: prospective high-resolution CT/bronchoscopic correlation. Chest 1994; 105: $1152-1162$. 